\title{
CONTRIBUIÇÃO DO DESIGN EM PROJETO DE VEÍCULO AÉREO NÃO TRIPULADO: PROPOSTA DE ESTRUTURA PARA AUMENTO DE AUTONOMIA
}

Rafael Mangiolardo Macedo Gomez (mangiolardo41@gmail.com) - Universidade do Sagrado Coração (USC).

Prof. Dr. João Carlos Riccó Plácido da Silva (joaocplacido@gmail.com) - Universidade do Sagrado Coração (USC).

Prof. ${ }^{a}$ Dr ${ }^{a}$. Sileide Aparecida de Oliveira Paccola (sileide.paccola@usc.br) - Universidade do Sagrado Coração (USC).

\section{RESUMO}

O interesse de empresas em pesquisa de plataformas autônomas, que vão substituir o homem em certas atividades, fez dos veículos aéreos não tripulados (VANTs), umas das alternativas para algumas destas atividades. $\mathrm{O}$ avanço de tecnologias nos últimos anos dos motores, de controles de voos, plataformas de transmissão, modelagem dinâmica, de métodos de controle automático para estabilização e regulação, entre outros, proporcionou a produção de drones mais seguros. Os Drones atraem muitos usuários civis pela vantagem de decolarem e pousarem com grande facilidade, também tendo muita manobrabilidade, como voar verticalmente e pairar, tendo vários cenários de aplicações civis para estes veículos, entre eles: proteção civil, investigação, captação de vídeo e fotografia, permitindo realizar um registro de imagem para vários tipos de desígnios. Um grande problema para esses equipamentos está relacionado à sua autonomia, visto que os modelos de VANTs atuais possuem uma capacidade de bateria limitada, interferindo no tempo de voo. Esse projeto objetiva estudar a forma e materiais da estrutura deste equipamento e apresentar uma estrutura inovadora que contribua para a ampliação da autonomia do equipamento VANT.

Palavras chave: Design de transporte; Design aerodinâmico; VANT; Estrutura. 


\section{INTRODUÇÃO}

\subsection{Justificativa}

O interesse de pesquisadores e empresas no desenvolvimento de plataformas autônomas, que possam substituir o homem em atividades consideradas perigosas e a criação de equipamentos que possam voar em ambientes hostis, tem aumentado nos anos recentes. A utilização de VANTs tem crescido substancialmente para muitas dessas atividades, pois não necessitam de pilotos, os controles são remotos ou autônomos e não requerem a intervenção humana. O projeto a ser desenvolvido justifica-se em função dos modelos de VANTS atuais possuírem baixa autonomia de voo.

\subsection{Objetivo}

O objetivo deste trabalho é levantar o estado da arte e da técnica em torno de drones e demonstrar como o design pode auxiliar neste tipo de projeto, verificando fatores como os drones, aerodinâmica, perfil aerodinâmico, voo aerodinâmico e o design aerodinâmico, criando uma ligação com as preocupações que o projeto deve ter para essa área.

\subsection{Drones}

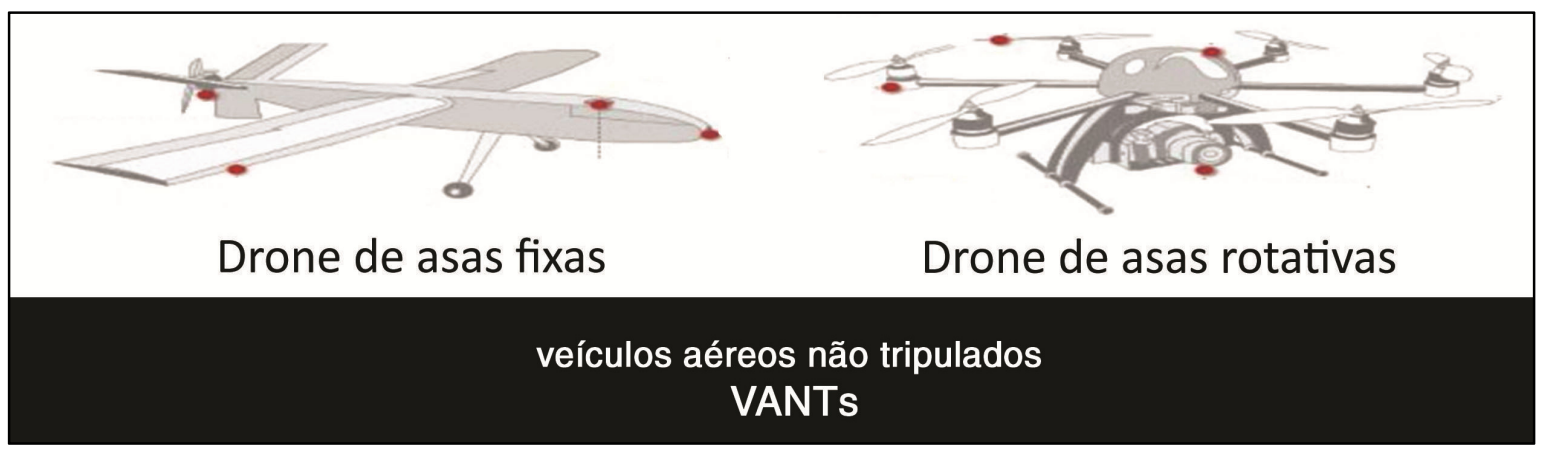

FIGURA 1 - Drone. Fonte: Elaboração do ator com dados de SANTOS (2013)

VANTs / Drones são aeronaves sem pilotos e operados por controle remoto. Dada a sua riqueza de possibilidade de aplicações e da popularização, havendo interesse de empresas em pesquisar, para substituir o homem em certas atividades tornado umas das alternativas para algumas destas atividades. Por exemplo, o "jornalismos drone” representa uma inovação para coberturas jornalísticas aéreas enfatizado por Simões et al. (2016).

Dada a sua riqueza de possibilidade de aplicações, desperta o interesse de melhorias. 
Demolinari (2016) apresenta referências para projetos de drones de asas fixas (aviões, planadores), e asas rotativas de monorotor (helicópteros) e multirotores (tricópteros, quadricópteros, hexacópteros e octocópteros). Apresenta um sistema com estrutura, motores, hélices, controladores de velocidades, controlador de voo, baterias, sensores e rádios. $\mathrm{Na}$ utilização destas ferramentas a quantidade de motores, influência capacidade de carga da estrutura dada pelo peso máximo de decolagem (25 kg até $150 \mathrm{~kg}$ e acima de $150 \mathrm{~kg})$.

Por outro lado, os Drones de asas rotativas são mais adaptados em aplicações civis principalmente o modelo quadricoptero com câmera acoplada, voltado para monitoramento de estruturas elétricas de difícil acesso localizadas em construções, segundo Santos (2013).

Sá (2012) apresenta a construção de um modelo quadrotor, com controlador PID para estabilização e movimentação vertical, baseado em alguns modelos de quadricópteros que possuem peso de 420 a $640 \mathrm{~kg}$ e autonomia de 12 a 30 minutos. Porém, um grande problema está relacionado à sua autonomia, visto que os modelos atuais têm capacidade limitada de bateria, que interfere no tempo de voo.

\section{REVISÃO TEÓRICA}

\subsection{Aerodinâmica}

A aerodinâmica é o estudo do movimento de fluidos gasosos, relativo às suas propriedades e características, e às forças que exercem em corpos sólidos neles imersos, conforme Rodrigues (2014)

Matos e Arêas (2014), explicam que a aerodinâmica vem das forças de sustentação, empuxo, peso, arrasto e ângulo de ataque, que produz as reações necessárias para a sustentação de um perfil aerodinâmico durante o voo.

\subsection{Perfil Aerodinâmico}

Rodrigues (2014) afirma que o perfil aerodinâmico é uma superfície projetada para obtenção de escoamento do vento relativo ao redor do objeto.

Conforme artigo de Silva e Bechepeche (2016), as principais partes do perfil são: a corda, o bordo de ataque, o bordo de fuga, o extradorso, o intradorso, a linha de curvatura média, arqueamento e espessura. Estas partes definem um perfil com seção bidimensional com formato aerodinâmico e geram sustentação a partir da variação da velocidade. 


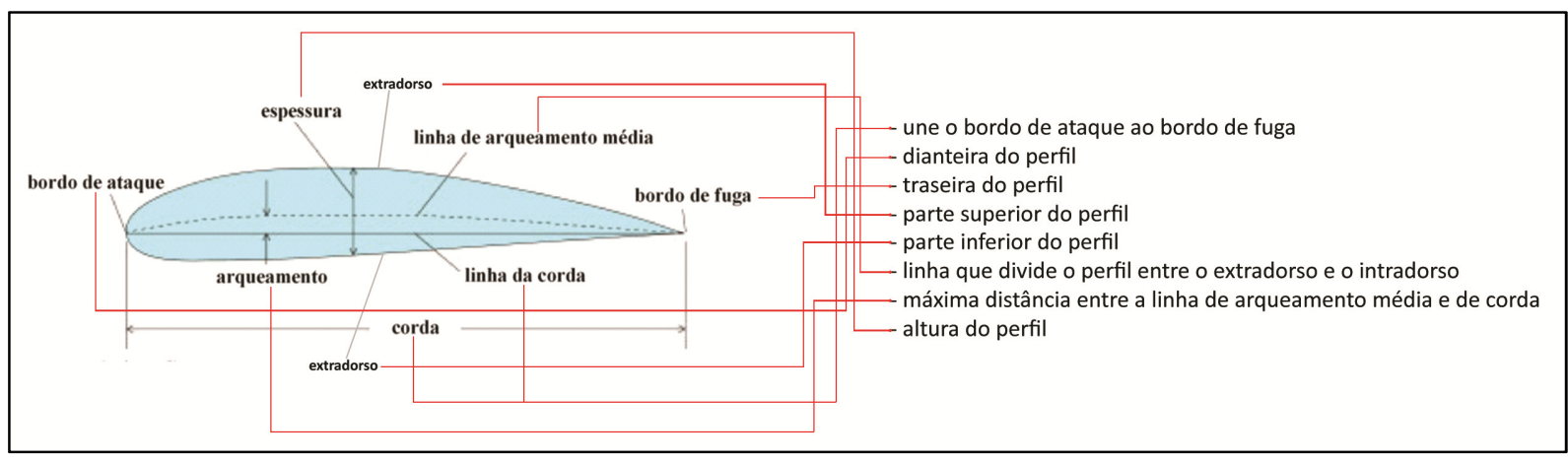

FIGURA 2 - Perfil aerodinâmico. Fonte: Elaboração do ator com dados de Rodrigues (2014) e Silva e

Bechepeche (2016)

Segundo Chediac (1989), o melhor aproveitamento das reações do vento relativo com o perfil aerodinâmico ocorre quando o ângulo está entre $90^{\circ}$ e $0^{\circ}$ graus criando uma superfície aerodinâmica. Os ângulos existentes se destacam: de ataque e de incidência. Especifica que o ângulo de ataque pode ser positivo, nulo e negativo.

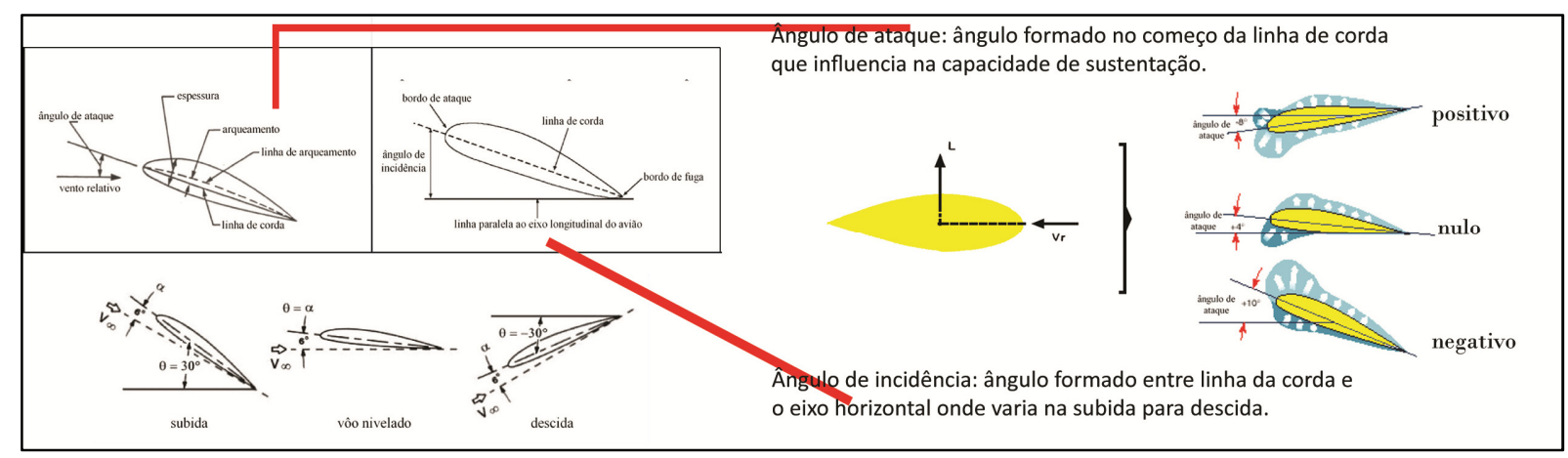

FIGURA 3 - Perfil aerodinâmico. Fonte: Elaboração do ator com dados de Chediac (1989) e de Rodrigues (2014)

Rodrigues (2014) ainda destaca a existência de três características aerodinâmicas de um perfil: a capacidade de geração de sustentação do perfil, a determinação da correspondente força de arrasto e o momento resultante ao redor do centro aerodinâmico. Por sua vez, coloca que o centro de pressão é dado a partir da distribuição de pressão sobre a superfície do perfil, obtida através de análises de modelos matemáticos e geométricos fundamentados na aerodinâmica. As análises obtidas resultantes a partir de um processo integrado a carga distribuída no objeto em porções, entre o bordo de ataque e de fuga e o ângulo de ataque, denomina um resultante aerodinâmico, considerado um grande centro de pressão $(\mathrm{CP})$ que passa da frente do perfil para um localizado atrás do objeto. 
Chediac (1989), menciona que a particularidade do perfil quanto à sustentação há dois tipos: simétrico e assimétrico. Sendo que o simétrico não apresenta variação do centro de pressão com a mudança do ângulo de ataque e o assimétrico tem uma grande variação do centro em relação ao ângulo. $\mathrm{O}$ centro de pressão $(\mathrm{CP})$ mencionado é um ponto imaginário onde ficam todas as forças aerodinâmicas de um objeto aerodinâmico.

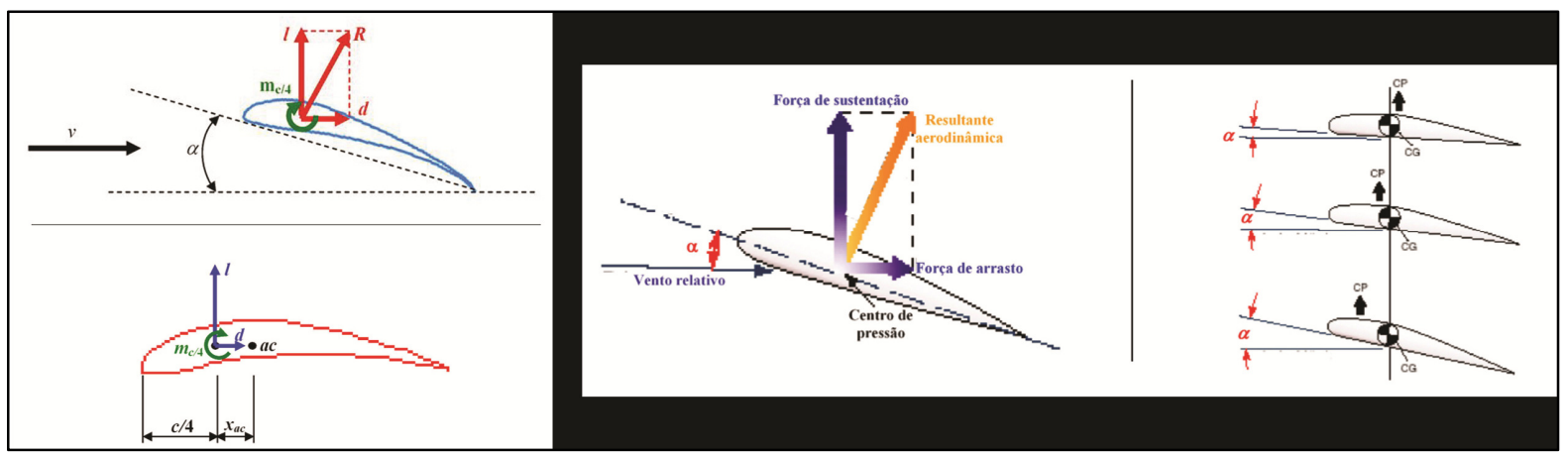

FIGURA 4 - Momentos em perfis e centro aerodinâmico / Centro de pressão e gravidade. Fonte: Elaboração do ator com dados de Rodrigues (2014)

\subsection{Voo Aerodinâmico}

Silva e Bechepeche (2016), afirmam que o voo é uma consequência do deslocamento do vento das diversas estruturas já mencionadas do perfil aerodinâmico que são construídas para a produção da força de sustentação, que surge através do deslocamento do vento no objeto. Machado (2011) complementa destacando a existência de três tipos de voo: o pairado, o vertical e à frente, sendo que o pairado pode ser com vento ou sem vento.

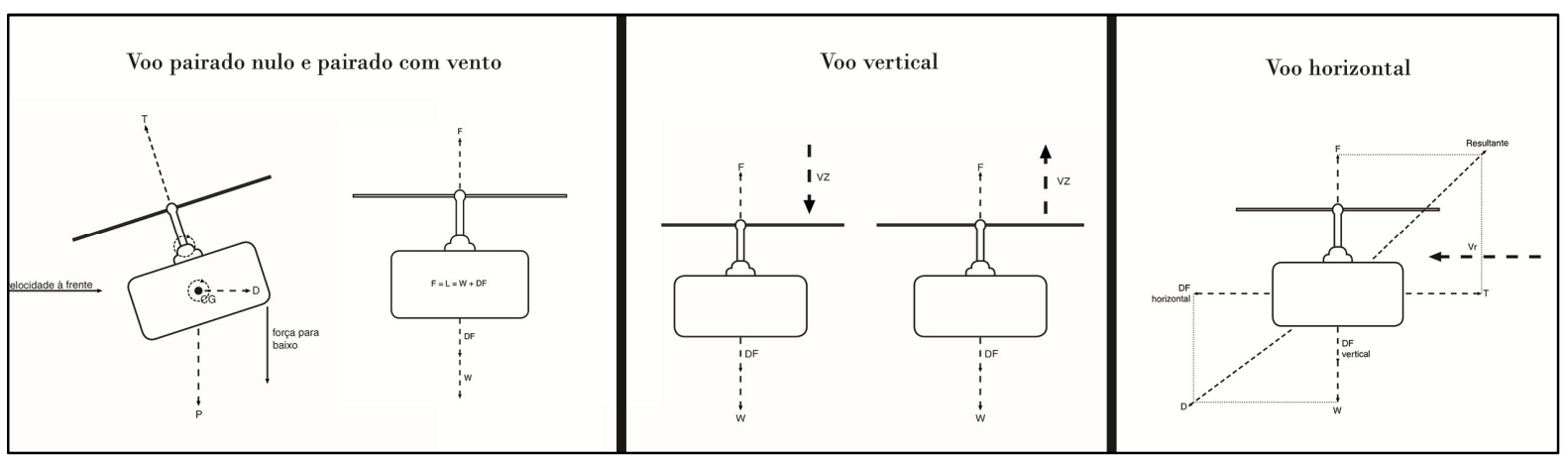

FIGURA 5 - Voo pairado, vertical, horizontal. Fonte: Elaboração do ator com dados de Machado (2011)

Segundo o Servúlo (2017), voo pairado é aquele que o objeto se encontra estável perto do solo. Machado (2011) explica que no voo pairado nulo, as pás em rotação produzem uma 
força para cima $(\mathrm{F})$, e o vento é empurrado para baixo, ao encontrar com a fuselagem, produz um arrasto (DF). A força deve ser igual à soma do peso (W) mais o arrasto, para que o vento seja nulo, a força também tem que ser igual à sustentação (L). No voo pairado com vento, ele coloca que a força, gera duas componentes a tração (T) e a sustentação (L) e o arrasto (D), também gera duas componentes. A força acaba anulando a tração e o vento relativo (Vr) mais os componentes do arrasto. Sendo que a sustentação anula o peso com a outra componente do arrasto.

Servúlo (2017) coloca que além do voo pairado existe o com deslocamento, sendo eles o vertical (sustentação e peso) e horizontal (tração e arrastro). Machado (2011) por sua vez afirma que o voo pairado é uma situação do voo vertical e o horizontal é um complemento do vertical

Voo vertical ocorre quando a velocidade á frente é nula, sendo a velocidade vertical (VZ) de subida (ascendente) e de descida (descendente), esses voos exigem uma ação sobre o peso coletivo e no aumento da sustentação (F) resultado na diminuição do peso (W) de (F > W), e na diminuição na sustentação $(\mathrm{F})$ com aumento do peso $(\mathrm{W})$ de $(\mathrm{F}<\mathrm{W})$. Há, também, ocorrência de arrastro (DF) que aumenta com VZ resultando em uma posição de equilíbrio constante quando $\mathrm{F}-\mathrm{W}=\mathrm{DF}$ no voo ascendente e quando o $\mathrm{F}+\mathrm{DF}=\mathrm{W}$ no voo descendente.

Voo horizontal ocorre quando a força de tração (T) é conseguida pela inclinação dos ângulos que aumenta a sustentação (L) na traseira e diminui a sustentação dianteira e provoca uma inclinação no objeto. A decomposição da sustentação em duas forças (vertical e inclinada) e a combinação de forças (peso e da sustentação), produz o surgimento da força tração do perfil em sentido contrário ao vento relativo (Vr). As variações dos ângulos inclinados das forças faz com que ocorra uma força de arrastro (D) contrária a tração. Portanto, conclui-se que a tração é inversamente proporcional à sustentação, provocando maior tração, maior inclinação, resultando em menor sustentação. O equilíbrio das forças aplicado no perfil, no voo horizontal, dentro do plano longitudinal, os somatórios de todas as forças e dos momentos em torno do centro de gravidade (CG) devem ser nulos. Pois de fato, o momento aerodinâmico no perfil é o arrastro (D) contrário a tração (T) que depende da posição do centro de gravidade.

\subsection{Design Aerodinâmico}

O Design aeronáutico é uma atividade que transmite a imagem de um ofício cercado de 
cálculos matemáticos, pois a arte de projetar aviões surgiu separada da engenharia, movida pela curiosidade e desafio de conquistar uma nova morada terrestre, segundo Oliveira (2010). Oliveira (2010), afirma que no Brasil, a EMBRAER empresa fabricante de aeronaves, hà um departamento de Pré-projeto composto por projetistas e engenheiros que geram propostas de novos aviões. Onde a maior parte dos projetistas não tem formação específica em aeronáutica. Raymer (1992), por sua vez, conceitua o design aeronáutico como uma disciplina separada da engenharia aeronáutica, diferente das disciplinas de aerodinâmica, estruturas, controles e propulsão. Um designer que pretende trabalhar na área aeronáutica deve ser versado nesta e muitas outras especialidades, mas tem que gastar o seu tempo fazendo "design", criando a descrição geométrica de objetos a serem construídos, em outras palavras criando desenho. No entanto, o trabalho do designer é mais mental, e se for talentoso, consegue passar suas ideias facilmente para o papel sem prejudicar o trabalho do engenheiro. Para estabelecer um novo conceito de avião a ser feito, os envolvidos devem estabelecer os requisitos previstos pelos estudos do mercado e do projeto, em seguida são estabelecidos os conceitos para atender os requisitos. Porém o projeto tem que passar por um especialista em dimensionamento para poder estimar o peso da aeronave a ser desenvolvida. O design tem que ser integrado nesta etapa trabalhando em análises e conceitos.

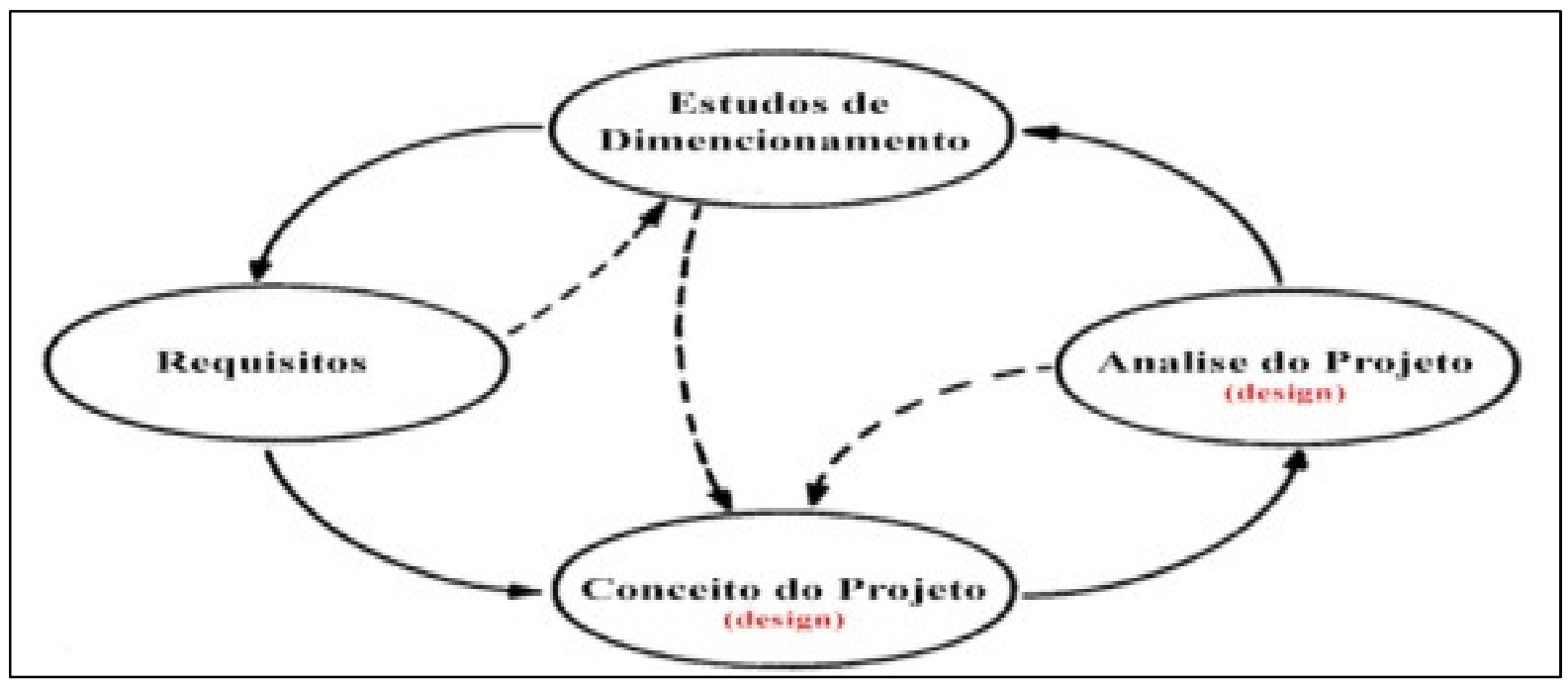

FIGURA 6 - Diagrama do processo de projeto aeronáutico. Fonte: Elaboração do ator com dados de Raymer (1992) e Oliveira (2010)

Raymer (1992) explica as fases do Design Aerodinâmico após a concepção do requisito classificando em: Conceptual Design (processo de novas ideias e problemas emergem onde o design mais recente é analisado); Preliminary Design (processo que começa quando as 
primeiras mudanças acabam onde é concebido o projeto preliminar) e Detali Design (processo que começa no desenvolvimento das peças em tamanhos reais a ser fabricadas).

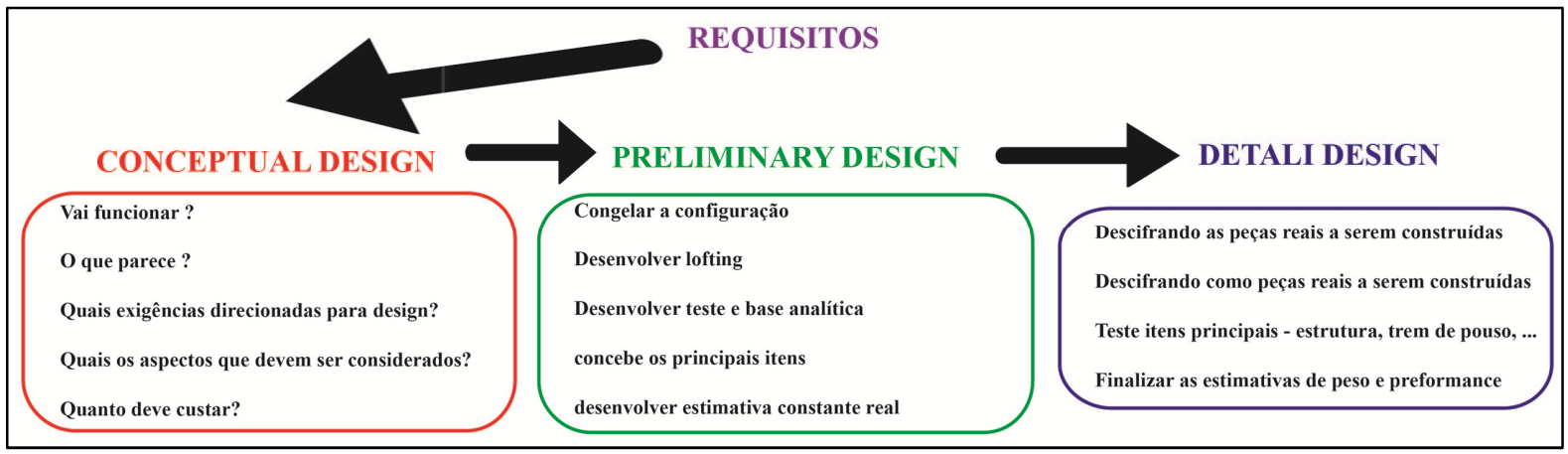

FIGURA 7 - Três fases do design de aeronave. Fonte: Elaboração do ator com dados de Raymer (1992)

Raymer (1992) destaca que o esforço real de designer começa com um sketch conceitual "esboço ou desenho". O sketch refere-se à geometria aproximada da asa e da cauda, a forma da fuselagem e os locais internos, como dos componentes principais dos motores, o cockpit, o compartimento da carga, local dos passageiros, o trem de pouso e os tanques de combustível. O sketch conceitual é usado para estimar a aerodinâmica e o peso comparado aos projetos anteriores. Desta feita são elaboradas as primeiras estimativas do peso total e peso do combustível necessário para realizar o projeto, pelo processo chamado "dimensionamento".

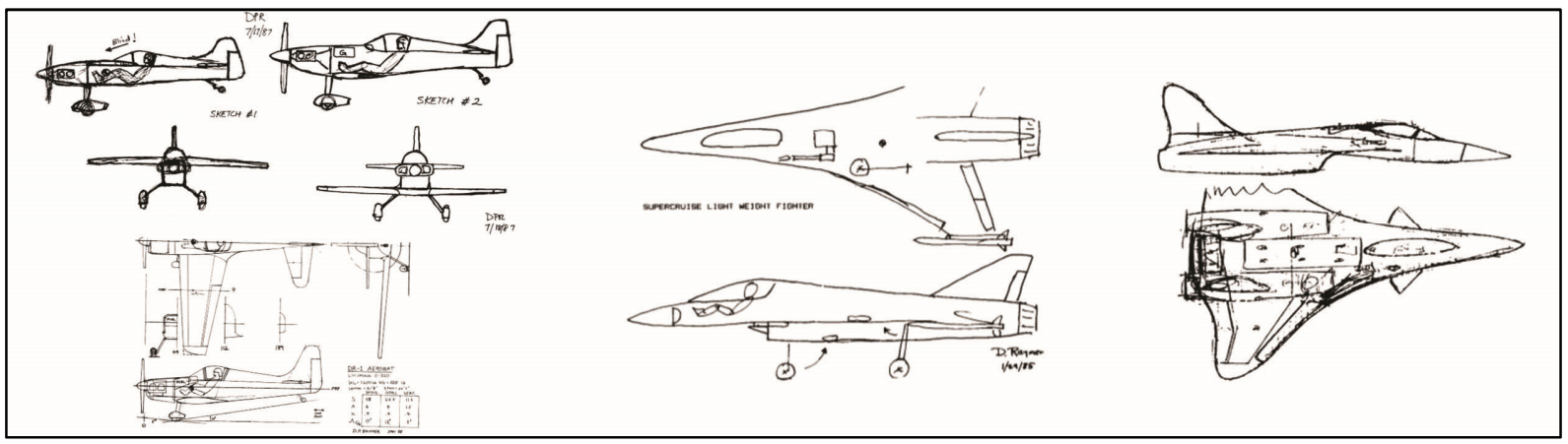

FIGURA 8 - Sketch conceitual de Daniel P. Raymer. Fonte: Elaboração do ator com dados de Raymer (1992).

\section{METODOLOGIA}

O objeto desta pesquisa será analisar as estruturas dos veículos aéreos não tripulados existentes atualmente no mercado, observando forma, materiais e desempenho da autonomia. Para o desenvolvimento do projeto, será adotada a metodologia proposta por LOBACH (2001). Dividiu-se o processo criativo em quatro fases: 


\section{1 fases}

- Fase de preparação: Desenvolveu-se análise e o conhecimento do problema. Pesquisa em livros e artigos científicos referentes a informações sobre aerodinâmica, perfil, voo e design.

- Fase de geração: Ampliou-se a revisão da literatura para realização do projeto e análise de similares da pesquisa de mercado sobre Drones. Para a escolha do modelo mais adequado, foi feita uma análise de como redesenhar uma nova estrutura com o objetivo de proporcionar o aumento da autonomia de voo.

- Fase de Avaliação: O Modelo Inspire 2 foi o escolhido para solucionar o problema, definir o painel de inspiração e o desenvolvimento da forma, para produção de ideias e geração de alternativas.

- Fase de Realização: Produção de ideias e geração de alternativas para realização da solução em conjunto com o desenho técnico e a realização do desenho 3D, aprofundamento das ilustrações finais, desenvolvimento das aplicações dos componentes, escolha do material e das cores e aplicação em simulador de túnel de vento.

\section{RESULTADOS E DISCUSSÃO}

\subsection{Resultado}

O Drone foi desenvolvido a partir de sete tópicos de resultados:

- O desenvolvimento das formas registra o começo da geração das ideias, baseado nos parâmetros do perfil aerodinâmico e no modelo Inspire 2, definindo as formas que apresentam aerodinâmicas mais eficientes.

- Esboços "Sketch" e desenho final, para tanto as formas aerodinâmicas em formato em um tubarão para obtenção do melhor da formato aerodinâmico do drone e visualmente agradável, com um furo passante de entrada e saída do ar para facilitar a decolagem diminuindo a pressão.

- Desenho técnico para melhor compreensão da forma em proporção métricas necessária para desenvolver o modelo final. Foi utilizado o programa AutoCAD, para realizar o desenho técnico com maior precisão.

- Utilizado o programa Blender, Modelagem 3D, impressão 3D, criando um modelo físico 
em três dimensões para melhor compreensão da forma.

- Verificação dos componentes do modelo escolhido para o dimensionamento e para verificação mais aprofundada.

- Estudo de cores e materiais para melhor compreensão do modelo. O material escolhido foi à fibra de carbono, por estar em diversos veículos de alta performance, automóveis e aeronaves. O estudo de cores foi baseado na escala de cores Pantone, verificamos modelos de cores chamativas entre cores quentes (amarelo, laranja, vermelho, etc.) e cores frias (azul, verde e violeta etc). Destas se destacarão os tons amarelados, laranjas, avermelhados, arroxeados e roseados. Descartando os tons azulados, por ser presente no céu e os esverdeados, por ser muito presente nas folhas de árvores.

- Túnel de vento, foi utilizado o software de aerodinâmica, Flow Design, compatível ao simulador de túnel de vento, para verificação aerodinâmica, submeteu-se o modelo 3D.

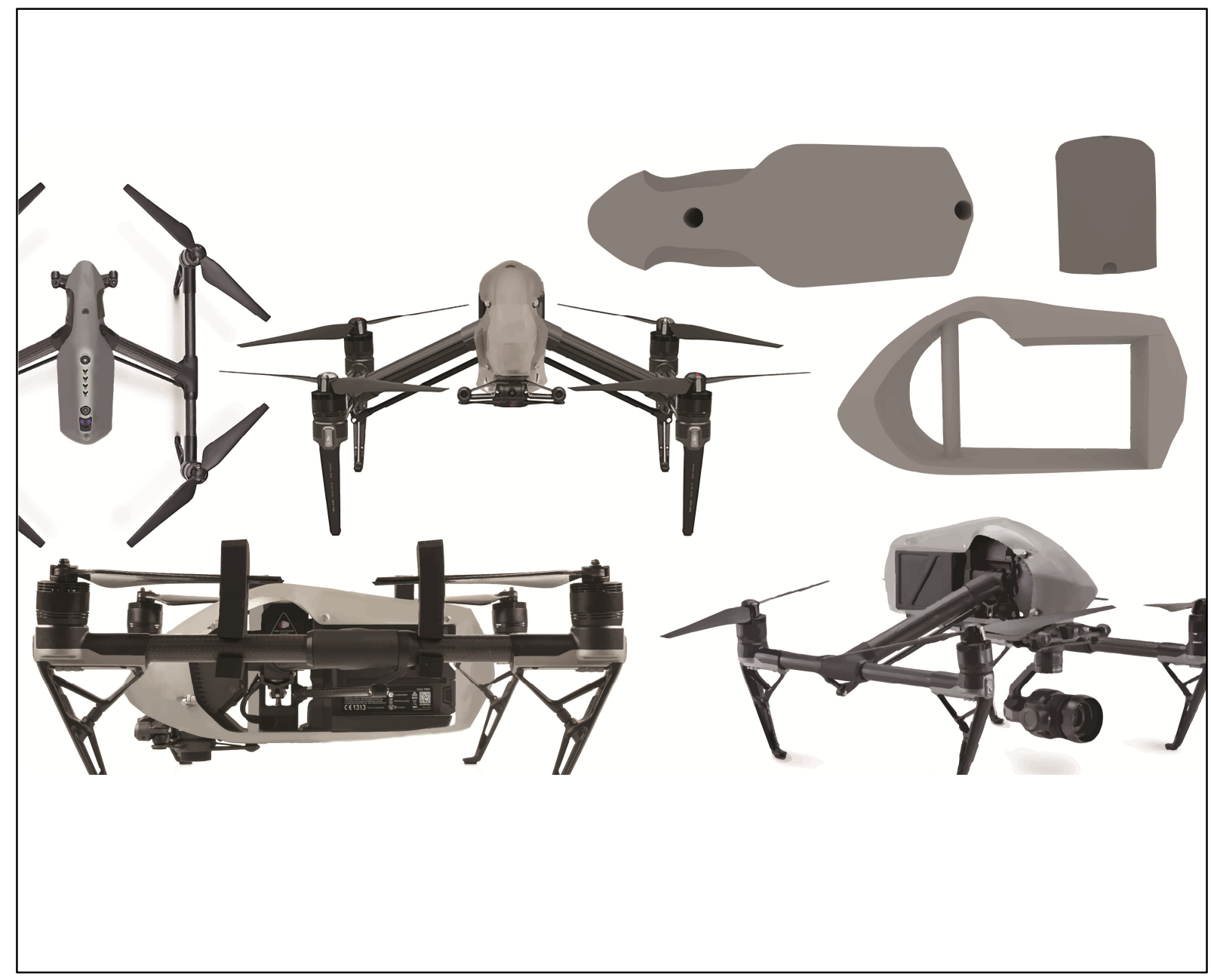

FIGURA 9 - Forma do drone. Fonte: Elaboração do ator. 


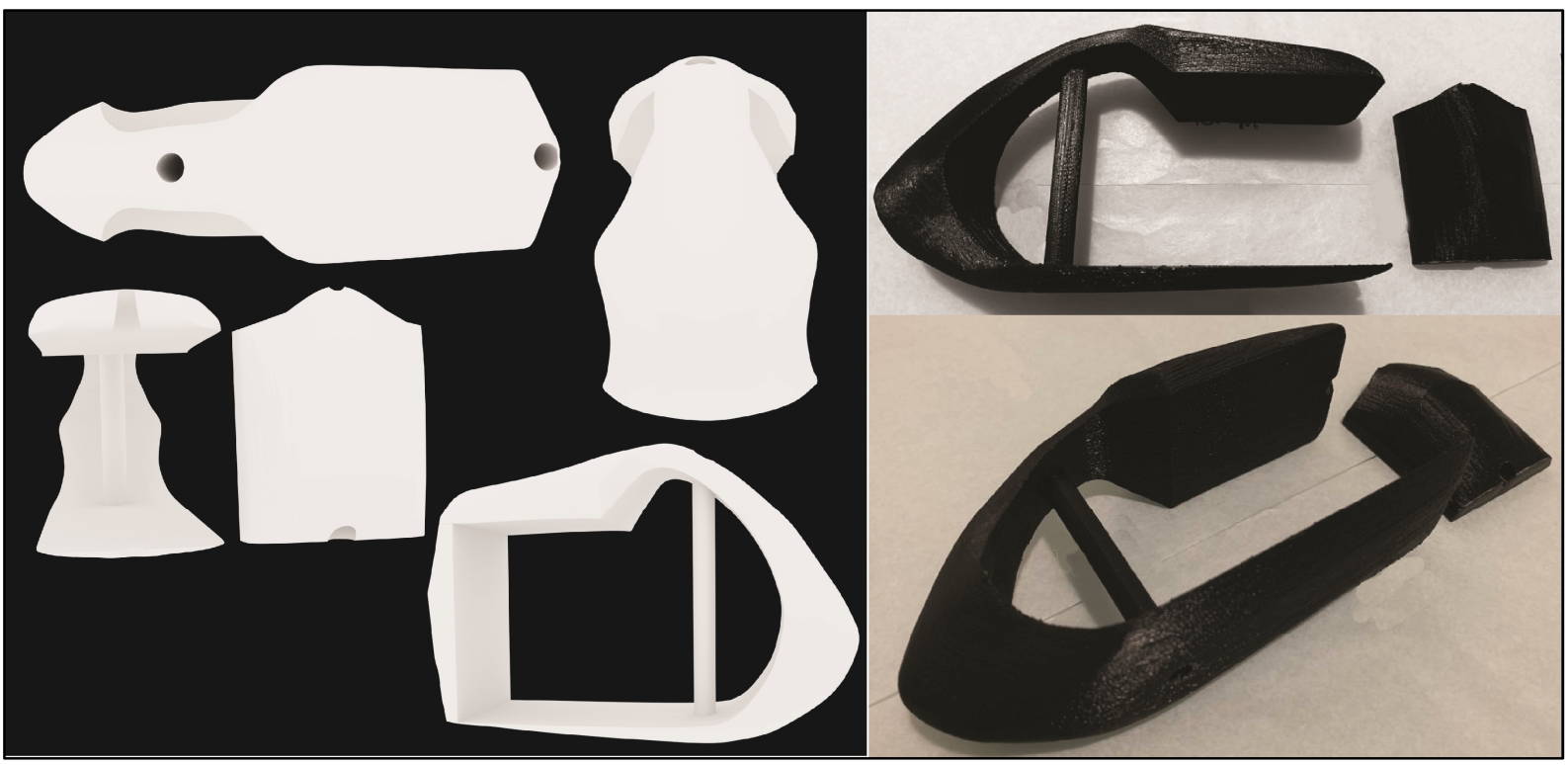

FIGURA 10 - Modelo 3D. Fonte: Elaboração do ator.
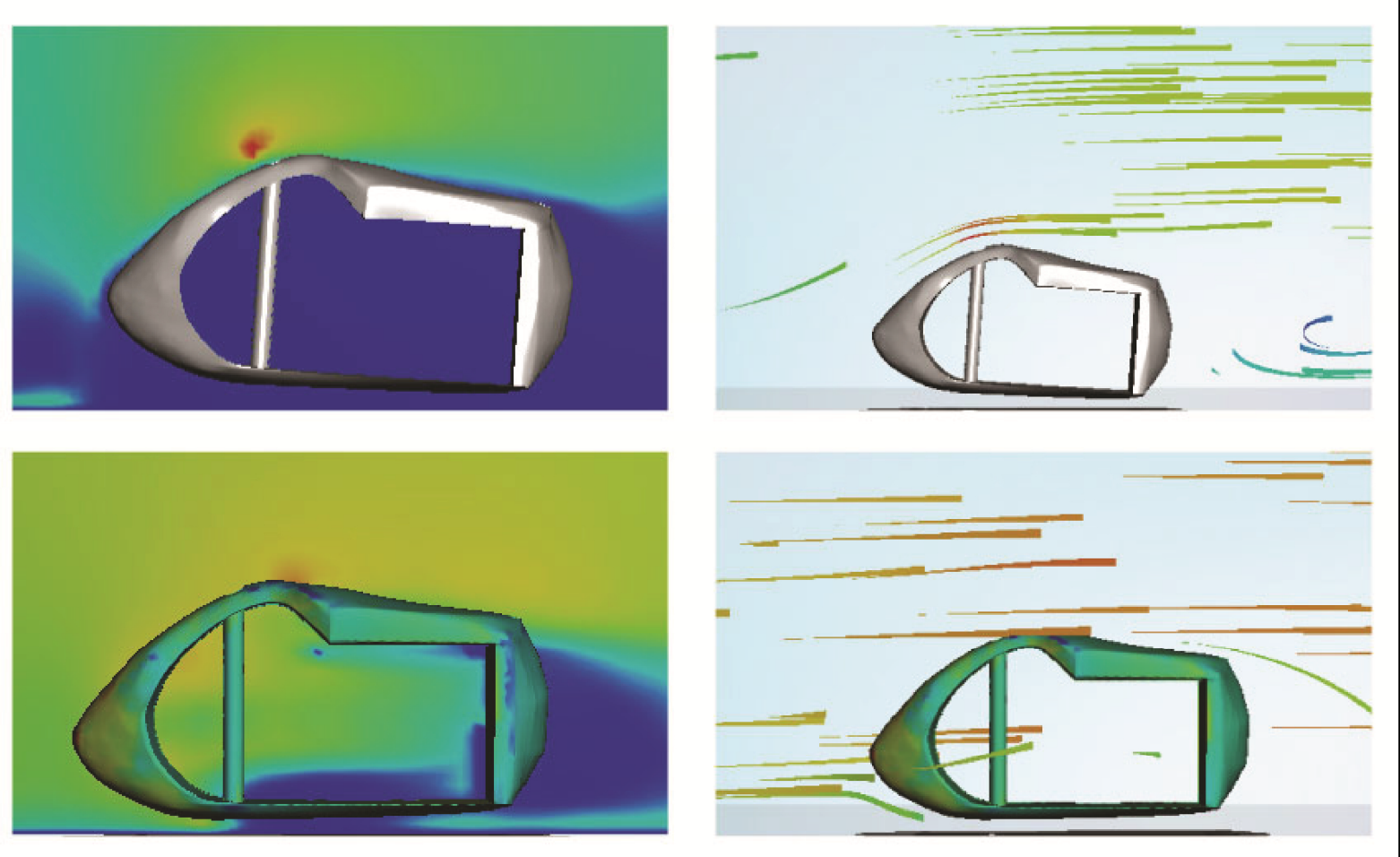

FIGURA 11 -Aerodinâmica (túnel de vento). Fonte: Elaboração do ator com dados do Software Flow Design.

\subsection{Discussão}

A Discussão foi abordada a partir dos resultados da simulação aerodinâmica Flow Design, com o modelo em uma velocidade de $1 \mathrm{~m} / \mathrm{s}$ à $15 \mathrm{~m} / \mathrm{s}$ referente a seis pontos a aerodinâmicos: 
- Ângulos de ataque $(\alpha)$ e incidência $(\theta)$ : mostrando os resultados da velocidade do vento de $0 \mathrm{~m} / \mathrm{s}$ à $38 \mathrm{~m} / \mathrm{s}$ submetidos aos ângulos de ataque de $6^{\circ}$ e de incidência na subida com ângulo de $30^{\circ}$, no nivelado com ângulo de $0^{\circ}$ e na decida com ângulo de $-30^{\circ}$.

- Passagem do vento relativo (Vr): mostra os resultados da passagem do vento com velocidade de $0^{\circ}$ à $32^{\circ}$ e o seu componente de sustentação (L). Submetendo aos ângulos de ataque de $-8^{\circ}, 4^{\circ}$ e $10^{\circ}$.

- Perda de sustentação (estol): mostra os resultados da perda de sustentação, com a passagem do vento de $0 \mathrm{~m} / \mathrm{s}$ à $30 \mathrm{~m} / \mathrm{s}$, com as características aerodinâmicas dos coeficientes de sustentação (R), de arrasto (d), de momento (mc/4), o centro aerodinâmico (ac) e a eficiência aerodinâmica. Submetendo aos ângulos de ataque de $20^{\circ}$ e $45^{\circ}$.

- Momento (mc/4) e centro aerodinâmico (ac): mostra os resultados do momento e centro aerodinâmico, com a passagem do vento relativo de 0 m/s à 37 m/s, em conjunto com sustentação (R), de arrasto (d). Submetendo aos ângulos de ataque de $\mathrm{O}^{\circ}$ e a cima.

- Centro de pressão (CP) e gravidade (CG): mostra os resultados dos centro, com a passagem do vento de 0 m/s à $32 \mathrm{~m} / \mathrm{s}$. Submetendo aos ângulos de ataque em 3 estágios ascendente.

- Voo pairado, vertical e horizontal: mostra os resultados do voo nas três etapas, pairado com a passagem do vento de $0 \mathrm{~m} / \mathrm{s}$ à $21 \mathrm{~m} / \mathrm{s}$, vertical com a passagem do vento de $0 \mathrm{~m} / \mathrm{s}$ à $24 \mathrm{~m} / \mathrm{s}$ e horizontal com a passagem do vento de $0 \mathrm{~m} / \mathrm{s}$ à $25 \mathrm{~m} / \mathrm{s}$. Submetendo as forças presente a cada estilo de voo.

Ao observar os seis pontos acima, verificou-se que o modelo possui uma aerodinâmica interessante, pois os movimentos de fluido gasosos, as forças de sustentação, empuxo, peso, arrasto e ângulo de ataque, que produzem as reações para a sustentação durante o voo a partir do movimento do vento com objeto, revelaram um modelo com uma aerodinâmica eficiente para o propósito de economia de energia.

Porém, ao abordar com mais afinco a economia de energia, falta estudar o resto dos componentes em conjunto com a carenagem, em um túnel de vento e em um cenário comparativo com os outros modelos estudados.

\section{CONCLUSÃO}

O desenvolvimento da pesquisa foi motivada em função dos modelos atuais possuírem baixa autonomia de voo e do desafio de projetar a estrutura de um VANT que proporcione o 
aumento da autonomia de voo com o aprimorando da forma. O projeto contribuiu desta forma para o aumento da autonomia de voo, aprimorando sua forma e utilização de materiais. O resultado positivo mostra a eficiência das etapas efetuadas.

O Conhecimento e analise dos tipos de estrutura de VANTs existentes atualmente mostraram que hà uma grande variedade, porém, com formas arbitrárias, de baixa autonomia, o que mostra a importância do trabalho.

Pesquisa de materiais leves, como a fibra de carbono, podem ser aplicada em estruturas de VANTs com eficiência.

Contribuir com o mercado de VANTs, com uma proposta inovadora desenvolvida por meio de pesquisa em design. O modelo se mostrou viável para a produção, atraente, eficiente, econômico e inovadora. Por fim, o projeto desenvolvido por meio de pesquisa em design aerodinâmico contribui para o aperfeiçoamento e melhora do desempenho dos veículos não tripulados e amplia as possibilidades de aumento de produção e comercialização.

\section{AGRADECIMENTOS}

Ao professor Dr. João Carlos Riccó Plácido da Silva pela atenção, apoio e orientação no desenvolvimento da Iniciação Científica (IC).

A professora Dr $^{\text {a }}$. Sileide Aparecida de Oliveira Paccola pela atenção, apoio e orientação no IC e no Projeto do Trabalho de Conclusão de Curso (TCC).

Nesses anos de convivência muito me ensinaram, contribuindo para meu crescimento científico e intelectual.

À Universidade do Sagrado Coração (USC) pela oportunidade de realização do IC e o TCC.

\section{REFERÊNCIAS}

CHEDIAC, Dirceu A. Peres. O helicóptero para pilotos e mecânicos teoria de vôo - conhecimentos técnicos. Rio de Janeiro: Editora Eapac, 1989.

DEMOLINARI, Humberto Cascardo. Projeto de Construção um Drone Hexacóptero. Trabalho de conclusão de curso apresentado ao Departamento de Engenharia Mecânica da Universidade Federal Fluminense, como requisito para obtenção do grau de Engenheiro Mecânico. Niterói: Universidade Federal Fluminense, 2016. 58 p.

LOBACH, Bernd. Design industrial - Bases para a configuração dos produtos industriais. São Paulo: Blucher, 2001.

MACHADO, Alessandro José; REISDORFER, Marcio Leandro; ALVES, João Marcos de Souza Alves. Conhecimento geral dos helicópteros: livro didático. Palhoça : UnisulVirtual, 2011. 202 p. : il. ; $28 \mathrm{~cm}$.

MATOS, Lizandra Salvador; ARÊAS, Pyter da Costa Venancio. Análise estática e dinâmica de uma pá de helicóptero. Dissertação apresentada ao Centro Federal de Educação Tecnológica Celso Suckow da Fonseca, para obtenção do título de Bacharel em Engenharia Mecânica Industrial. Rio de Janeiro: CEFET/RJ, 2014. 87 p. 
OLIVEIRA, Marcelo Silva. AERONAVE DE TREINAMENTO PRIMÁRIO/BÁSICO: Análise do sistema de instrução de voo, dos fatores de engenharia e sua implicação nos requisitos de projeto de uma nova aeronave. Tese apresentada à Pós-Graduação em Arquitetura e Urbanismo da Universidade Presbiteriana Mackenzie, para obtenção do Título de Doutor em Arquitetura e Urbanismo. São Paulo: Universidade Presbiteriana Mackenzie, 2010. 225 P.

RAYMER, Daniel P. Aircraft Design: A conceptual approach. Washington D.C: AIAA American Institute of Aeronautics and Astronautics, 1992.

RODRIGUES, Luiz Eduardo Miranda José. Fundamentos da Engenharia Aeronáutica com Aplicações ao Projeto SAE-AeroDesign: Aerodinâmica e Desempenho. Salto: 1973. Disponível em: <www.engbrasil.eng.> Acesso em: 12 ago. 2017.

SÁ, Rejane Cavalcante. Construção, modelagem dinâmica e controle PID para estabilidade de um veículo aéreo não tripulado do tipo quadrirotor. Dissertação de Mestrado apresentada ao Programa de Pós-Graduação em Engenharia de Teleinformática da Universidade Federal do Ceará, como parte dos requisitos para obtenção do grau de Mestre em Engenharia de Teleinformática. Fortaleza: UFC, 2012. 74 p.

SANTOS, Diego Vinicius dos. Veiculo aéreo não tripulado para monitoramento através de uma câmera. Trabalho de Conclusão de Curso apresentado ao curso de Graduação em Engenharia Elétrica da Pontifícia Universidade Católica do Paraná, como requisito à obtenção do título de Engenheiro Eletricista. Curitiba: PUCPR, 2013. $61 \mathrm{p}$.

SÉRVULO. Apostila de helicóptero - conhecimentos técnicos. Disponível em: <file://C:/Users/User/AppData/Local/Temp/Rar\$DIa0.333/Conhecimentos\%20técnicos\%20-

$\% 20$ Helicóptero\%20-\%20[www.canalpiloto.com.br].pdf> in: <http://canalpiloto.com.br/materiais-para-estudode-aviacao-download/> Acesso em: 10 ago. 2017.

SÉRVULO. Apostila de helicóptero - teoria de voo. Disponível em: <file:///C:/Users/User/AppData/Local/Temp/Rar\$DIa0.580/Teoria\%20de\%20voo\%20-\%20Helicóptero\%20-

$\% 20$ [www.canalpiloto.com.br].pdf> in: < http://canalpiloto.com.br/materiais-para-estudo-de-aviacaodownload/> Acesso em: 10 ago. 2017.

SILVA, S.; BECHEPECHE, A. P. Análise da força de sustentação em uma aeronave de asas rotativas e demonstração do voo de um aeromodelo Align Trex-4500 Helicorter. In: Anais do I Simpósio Nacional de Ciências e Engenharias (SINACEN), Anápolis, v. 1, p. 11-15, 26-28 out. 2016.

SIMÕES, Antonio; SILVA, Fernando Firmino da; AZÊVEDO, Arão de ... [et al]. Drone no jornalismo: implicações éticas e de mobilidade. Revista Latina-Americana de Jornalismo - Âncora. João Pessoa, ano 3, v. 3, n. 2, p. 125-140, jul./dez. 2016. 